\title{
Telemedicine delivery of patient education in remote Ontario communities: feasibility of an Advanced Clinician Practitioner in Arthritis Care (ACPAC)-led inflammatory arthritis education
} program

\author{
Kelly Warmington' \\ Carol Flewelling ${ }^{2}$ \\ Carol A Kennedy 3,4 \\ Rachel Shupak ${ }^{5}$ \\ Angelo Papachristos ${ }^{5}$ \\ Caroline Jones ${ }^{5}$ \\ Denise Linton ${ }^{3}$ \\ Dorcas E Beaton ${ }^{3,4,6-8}$ \\ Sydney Lineker ${ }^{9}$ \\ 'Learning Institute, The Hospital \\ for Sick Children, ${ }^{2}$ Telemedicine \\ Program, ${ }^{3}$ Musculoskeletal Health \\ \& Outcomes Research, St. Michael's \\ Hospital, ${ }^{4}$ Institute for Work \& Health, \\ ${ }^{5}$ Martin Family Centre for Arthritis \\ Care \& Research, St. Michael's \\ Hospital, ${ }^{6}$ Graduate Department \\ of Health Policy, Management and \\ Evaluation, ${ }^{7}$ Graduate Department of \\ Rehabilitation Science, ${ }^{8}$ Department \\ of Occupational Science and \\ Occupational Therapy, University \\ of Toronto, ${ }^{9} \mathrm{The}$ Arthritis Society \\ (Ontario Division), Toronto, ON, \\ Canada
}

This article was published in the following Dove Press journal:

Open Access Rheumatology: Research and Reviews

24 February 2017

Number of times this article has been viewed

Objective: Telemedicine-based approaches to health care service delivery improve access to care. It was recognized that adults with inflammatory arthritis (IA) living in remote areas had limited access to patient education and could benefit from the 1-day Prescription for Education (RxEd) program. The program was delivered by extended role practitioners with advanced training in arthritis care. Normally offered at one urban center, RxEd was adapted for videoconference delivery through two educator development workshops that addressed telemedicine and adult education best practices. This study explores the feasibility of and participant satisfaction with telemedicine delivery of the RxEd program in remote communities.

Materials and methods: Participants included adults with IA attending the RxEd program at one of six rural sites. They completed post-course program evaluations and follow-up interviews. Educators provided post-course feedback to identify program improvements that were later implemented.

Results: In total, 123 people (36 in-person and 87 remote, across 6 sites) participated, attending one of three RxEd sessions. Remote participants were satisfied with the quality of the videoconference ( $\%$ agree/strongly agree): could hear the presenter $(92.9 \%)$ and discussion between sites (82.4\%); could see who was speaking at other remote sites $(85.7 \%)$; could see the slides (95.3\%); and interaction between sites adequately facilitated (94.0\%). Educator and participant feedback were consistent. Suggested improvements included: use of two screens (speaker and slides); frontal camera angles; equal interaction with remote sites; and slide modifications to improve the readability on screen. Interview data included similar constructive feedback but highlighted the educational and social benefits of the program, which participants noted would have been inaccessible if not offered via telemedicine.

Conclusion: Study findings confirm the feasibility of delivering the RxEd program to remote communities by using telemedicine. Future research with a focus on the sustainability of this and other models of technology-supported patient education for adults with IA across Ontario is warranted. Keywords: rheumatoid arthritis, feasibility, patient satisfaction, telehealth, tele-education

\section{Introduction}

Inflammatory arthritis (IA) is a growing burden in Canada. ${ }^{1}$ It is estimated to affect more than 1 million $^{2}$ of the 36 million Canadians. ${ }^{3}$ The number of individuals with rheumatoid arthritis (RA), the most common inflammatory condition, has well surpassed
Correspondence: Kelly Warmington Learning Institute, The Hospital for Sick Children, 555 University Avenue, Toronto, M5G IX8, ON Canada Tel (4I6) 8I3-7654 Email kelly.warmington@sickkids.ca 
the capacity of rheumatologists in Ontario to effectively care for these patients. ${ }^{4}$ Although new models of arthritis care continue to advance in rural areas, ${ }^{5,6}$ adults with IA still represent a significantly undertreated and growing population. ${ }^{1,5}$ Patient education is well recognized as an essential component of specialized arthritis care models. ${ }^{1,7-10}$ However, access to care, and importantly, to patient education is lacking in remote areas in Ontario.

Arthritis patient education can take many forms and, depending on the program, is associated with improvements in disease knowledge, ${ }^{11-17}$ disease self-management, ${ }^{18,19}$ and coping ability. ${ }^{20-24}$ These outcomes are known to reduce health care utilization and costs to the health care system and, importantly, improve quality of life for people living with chronic disease. ${ }^{18,19,25}$ However, there remains a gap between the education required to successfully manage a chronic condition and the education that primary care practitioners, and even physician specialists, can provide in treatment-focused care. The targeted education that is available to patients in larger urban centers is often inaccessible to those living in rural Ontario.

Offering an education program, such as the "Prescription for Education" (RxEd) program, to individuals with IA, in their communities, is one way to address this gap. The effectiveness of the RxEd program was validated in $2011 .^{26}$ A pilot, wait-listed controlled study demonstrated that a 1-day IA education program delivered by an interprofessional arthritis care team was feasible and improved arthritis self-efficacy and other secondary outcomes in people with arthritis. This was apparent in people with different stages of the disease and with disease duration ranging from newly diagnosed to 48 years. The program was expanded to include telemedicine delivery when Advanced Clinician Practitioner in Arthritis Care (ACPAC)-trained clinicians working in rural and suburban areas across Ontario recognized the potential benefits of the RxEd program for people with IA in their communities. Delivering program content via telemedicine technology (videoconferencing) is an accessible, learner-centered approach to education that supports disease self-management.

A number of studies have explored the use of telemedicine for patient education and self-management among individuals with chronic diseases. They have determined that telemedicine is indeed a feasible method of delivery. Jaglal et $\mathrm{al}^{27}$ evaluated the delivery of a 6-week chronic disease selfmanagement program, comparing two telemedicine formats, point-to-point videoconferencing and multipoint conference design. This study concluded that the self-management program could be successfully delivered by using telemedicine and showed that outcomes were similar across the two groups (improved self-efficacy, positive health behaviors, and health status). Another group explored the feasibility and efficacy of a telehealth stroke self-management program for rural participants and found this program to be well received by all participants and was associated with improvement in patient outcomes, compared to a wait-listed control group. ${ }^{28,29}$ In addition, several studies have explored the feasibility and effectiveness of using a variety of telemedicine technologies for diabetes education. ${ }^{30-33}$ These studies reported improvements in clinical outcomes, and they report assisting patients with the management of their disease. However, only a few have directly compared telemedicine to in-person delivery. As with our prospective study comparing the effectiveness of telemedicine and in-person delivery of $\mathrm{RxEd},{ }^{34}$ they found similar trends in outcomes over time when comparing different modes of delivery. ${ }^{27,29}$

This project sets out to achieve two objectives: first, to understand the feasibility of using videoconferencing to deliver the RxEd program, reported herein, and second, to compare telemedicine delivery of RxEd with face-to-face (in-person) delivery. In a separate publication, ${ }^{34}$ we report on the two modes of delivery in terms of patient outcomes including arthritis self-efficacy, arthritis knowledge, coping efficacy, illness intrusiveness, and effective consumer.

The purpose of the present study was to explore the feasibility of and participant satisfaction with telemedicine delivery of the RxEd program by triangulating quantitative and qualitative feedback from RxEd participants at remote sites with input from the ACPAC-trained educators and facilitators.

\section{Materials and methods The RxEd program}

The RxEd program, a 1-day education session for adults with IA, was developed in response to a recognized gap in arthritis care. Patients' knowledge of their disease, and in turn, their ability to manage it, was lacking. The RxEd curriculum was developed in collaboration with arthritis care professionals, a person with arthritis, and an adult learning specialist ${ }^{26}$ and based on the results of a patient-centred needs assessment.

The content of the program focuses on helping participants better understand their arthritis and manage the pain and other challenges associated with this chronic disease. The session is delivered by an interprofessional arthritis care team and includes short presentations, panel discussions, 
time for questions and answers, and interactive small group, facilitator-led activities. Each remote site has a local extended role practitioner (trained through the ACPAC program) ${ }^{35}$ who provides in-person facilitation.

\section{Telemedicine delivery of RxEd}

In order to adapt the RxEd Program for telemedicine delivery, two professional development workshops were offered to both the interprofessional educators in Toronto and the facilitators at the remote sites. The workshops focused on videoconferencing fundamentals and the use of videoconferencing specifically for patient education. They incorporated videoconferencing technology, linking various sites, and simulated the RxEd learning experience. Emphasis was placed on the importance of applying sound patient education and adult learning principles in this unique virtual environment. The workshops demonstrated that technology can be manipulated to optimize the sense of social presence by using set camera positions and multiple microphones. Guidelines for slide presentations were also shared. Most importantly, the workshop modeled effective teaching strategies to actively engage remote participants.

The RxEd program was delivered to learners in Toronto (in-person) and via videoconferencing technology to participants at six remote sites, including Thunder Bay, Sault Ste. Marie, Sudbury, Timmins, Orangeville, and Brampton. Didactic presentations, as well as the panel discussions, were transmitted to the remote sites. One local ACPAC-trained physiotherapist or occupational therapist led small group activities at each site, answered participants' questions, managed the videoconferencing technology, and facilitated participants' interactions with the other sites.

\section{Recruitment}

Participants included RxEd program attendees (patients), as well as the RxEd program faculty (this included the educators delivering the content at the in-person site and the local facilitators at each of the remote sites).

Patients were recruited from arthritis care clinics at an urban teaching hospital (in-person site), as well as through six ACPAC extended role practitioners working across six rural and remote Ontario communities (remote sites). Program attendees who were eligible to participate included adults (aged $\geq 18$ years) with IA attending one of three full-day RxEd education sessions held in the fall of 2012, spring of 2013, or fall of 2013. Attendees had to have been diagnosed, by a clinician, with one of the following IA-related disorders: RA, psoriatic arthritis (PsA), systemic lupus erythematosus
(SLE), inflammatory bowel disease (IBD), or gout. Participants at remote sites who consented to be contacted for follow-up research were invited to participate in the qualitative interviews. Attendees who could not complete the survey or interview in English were excluded.

All RxEd program attendees were invited to participate in the program evaluation. They each received a study introduction package, including evaluation forms prior to the beginning of the 1-day session. Following the RxEd session, attendees were asked to indicate, in writing, their willingness to be contacted for the purposes of follow-up research. Approximately 1 week after the session, a research coordinator called those individuals who agreed to be contacted over the phone. Attendees were provided with details of the research study and asked whether they were willing to participate. If they agreed, they were mailed a study consent form for review. About 1 week after mailing the consent form, the research coordinator called the attendee to answer any questions and, if appropriate, obtain consent to participate. The research coordinator obtained verbal consent using a structured, approved consent checklist. This study received ethics approval from St. Michael's Hospital Research Ethics Board.

\section{Immediate post-program participant feedback}

RxEd attendees completed a paper-based program evaluation immediately following their education session. Following each session, local facilitators returned participants' anonymous evaluation forms to the research coordinator by secure courier. The evaluation included demographic information including age, sex, education, living situation, as well as diagnosis, disease duration, disease activity, and disability.

Disease activity was measured by using the rapid assessment of disease activity index,${ }^{36}$ and an abbreviated, eight-item, version of the Health Assessment Questionnaire (HAQ-8) was used to measure disability. ${ }^{37,38}$

The evaluation included 16 items rated on a 4-point scale (ie, strongly agree, agree, disagree, and strongly disagree). Items addressed participants' overall impressions and more specifically their perceptions of the quality of the videoconferencing, presentations, and facilities as well as an open-ended space for comments. Because the present study was focusing on the feasibility of telemedicine delivery of $\mathrm{RxEd}$, it reports on participants' overall impressions (whether or not the session met expectations; willingness to recommend the program to someone else with IA) and their views on the quality of the videoconferencing (ability to hear the 
presenter, ability to hear participants at other sites, ability to see who was speaking at the remote sites, ability to see the presentation slides, and adequate facilitation of interaction between sites).

\section{Post-program faculty (educator/ facilitator) feedback}

Following each session, faculty were asked to complete a 2-page feedback form (Table 1). The form included openended comment boxes addressing 1) the quality of the videoconference including audio, visual, and other technical considerations; 2) the quality of interaction between sites; 3 ) the small group learning activities including timing, task completion, and group dynamics; and 4) any other feedback. Feedback was discussed at a debriefing meeting, and action items were compiled and implemented in the following session(s) in keeping with quality improvement methodology. ${ }^{39}$

\section{Follow-up participant interviews}

Semi-structured interviews were conducted over the phone by the research coordinator and digitally audio-recorded for verbatim transcription. Two members of the research team independently coded the transcripts and conducted a thematic analysis. The interviews were based on a topic guide addressing two main issues: 1) the usefulness of the RxEd program (participants' expectations of the program, whether their expectations were met, usefulness of the information provided, and perceived benefits of the program), and 2) the quality of the videoconferencing (ability to see and hear the presenters, ability to hear the discussion between sites, and usefulness of the interaction between sites).

Table I Feedback form content: Prescription for Education (RxEd) telemedicine post-session reflection sheet for faculty

\begin{tabular}{l} 
Demographics \\
I. Session date \\
2. Site \\
\hline Open-ended comments \\
\hline I. Quality of the videoconference - consider technical issues such as \\
ability to hear presenter, hear discussion between participants at \\
different sites, ability to see who was speaking at remote sites, and \\
ability to see the slides \\
2. Interaction between sites - Was there adequate facilitation? How \\
could it be improved? \\
3. Small group learning/activities - Was your group able to accomplish \\
the task? Do you have any comments about: content of the \\
discussion, group dynamics, etc.? \\
4. Other comments
\end{tabular}

\section{Results}

In order to examine the feasibility of delivering RxEd via telemedicine, the present study reports primarily on the characteristics and perceptions of those participating remotely. Table 2 lists the characteristics of in-person participants for comparison.

\section{Immediate post-program participant feedback}

In total, 123 program attendees participated in one of three sessions delivered over six sites. Eighty-two percent (36 inperson and 87 remote) completed the post-program evaluation. There were no significant differences between groups in age, sex, diagnosis, disease activity, disease duration, or disability (Table 2). On average, remote participants were 58.6 years old (standard deviation $[\mathrm{SD}]=13.3$ ), and most were female $(n=76 ; 87.4 \%)$, had a postsecondary education

Table 2 Characteristics of participants by group

\begin{tabular}{|c|c|c|c|}
\hline Patient characteristics & $\begin{array}{l}\text { Remote } \\
(n=87)\end{array}$ & $\begin{array}{l}\text { In-person } \\
(n=36)\end{array}$ & $P$-value* \\
\hline Age (years) & $\begin{array}{l}58.58 \\
(13.26)\end{array}$ & $\begin{array}{l}56.80 \\
(13.09)\end{array}$ & 0.56 \\
\hline Sex (female) & 76 (87.4\%) & 22 (9l.7\%) & 0.56 \\
\hline \multicolumn{4}{|l|}{ Education level } \\
\hline $\begin{array}{l}\text { Primary/elementary school } \\
\text { or less }\end{array}$ & $2(2.3 \%)$ & 0 & 0.50 \\
\hline Secondary school & $33(38.4 \%)$ & $9(39.1 \%)$ & \\
\hline Postsecondary school & 45 (52.3\%) & $14(60.9 \%)$ & \\
\hline Respondent unsure & $6(7.0 \%)$ & 0 & \\
\hline \multicolumn{4}{|l|}{ Living arrangements } \\
\hline Alone & $18(21.2 \%)$ & $8(33.3 \%)$ & 0.22 \\
\hline With one person or more & 67 (78.8\%) & $16(66.7 \%)$ & \\
\hline \multicolumn{4}{|l|}{ Diagnosis } \\
\hline Rheumatoid arthritis (RA) & $52(74.3 \%)$ & I 8 (75.0\%) & 0.19 \\
\hline Psoriatic arthritis (PsA) & $6(8.6 \%)$ & $3(12.5 \%)$ & \\
\hline $\begin{array}{l}\text { Systemic lupus } \\
\text { erythematosus (SLE) }\end{array}$ & I (I.4\%) & $2(8.3 \%)$ & \\
\hline Gout & $2(2.9 \%)$ & I (4.2\%) & \\
\hline $\begin{array}{l}\text { Inflammatory bowel disease } \\
\text { (IBD)-related arthritis }\end{array}$ & I (I.4\%) & $0(0 \%)$ & \\
\hline $\mathrm{RA}+(\mathrm{Ps} A$ or SLE or IBD) & $8(11.4 \%)$ & $0(0 \%)$ & \\
\hline Disease duration (years) & $7.92(11.15)$ & II.57 (I3.59) & 0.18 \\
\hline \multicolumn{4}{|l|}{ RADAI score } \\
\hline $\begin{array}{l}(0 \text { to } 10,10=\text { greater } \\
\text { disease activity) }\end{array}$ & $4.67(1.82)$ & $4.35(1.77)$ & 0.46 \\
\hline \multicolumn{4}{|l|}{ HAQ 8-item disability } \\
\hline $\begin{array}{l}\text { score } \\
(0-3,3=\text { greater disability })\end{array}$ & $0.62(0.38)$ & $0.57(0.46)$ & 0.59 \\
\hline
\end{tabular}

Notes: Categorical data: frequency (\%); continuous data: mean (standard deviation). *P: differences across groups $\left(\chi^{2}\right.$ tests for categorical variables and ANOVA for continuous variables).

Abbreviations: ANOVA, analysis of variance; HAQ, Health Assessment Questionnaire; RADAI, rapid assessment of disease activity index. 


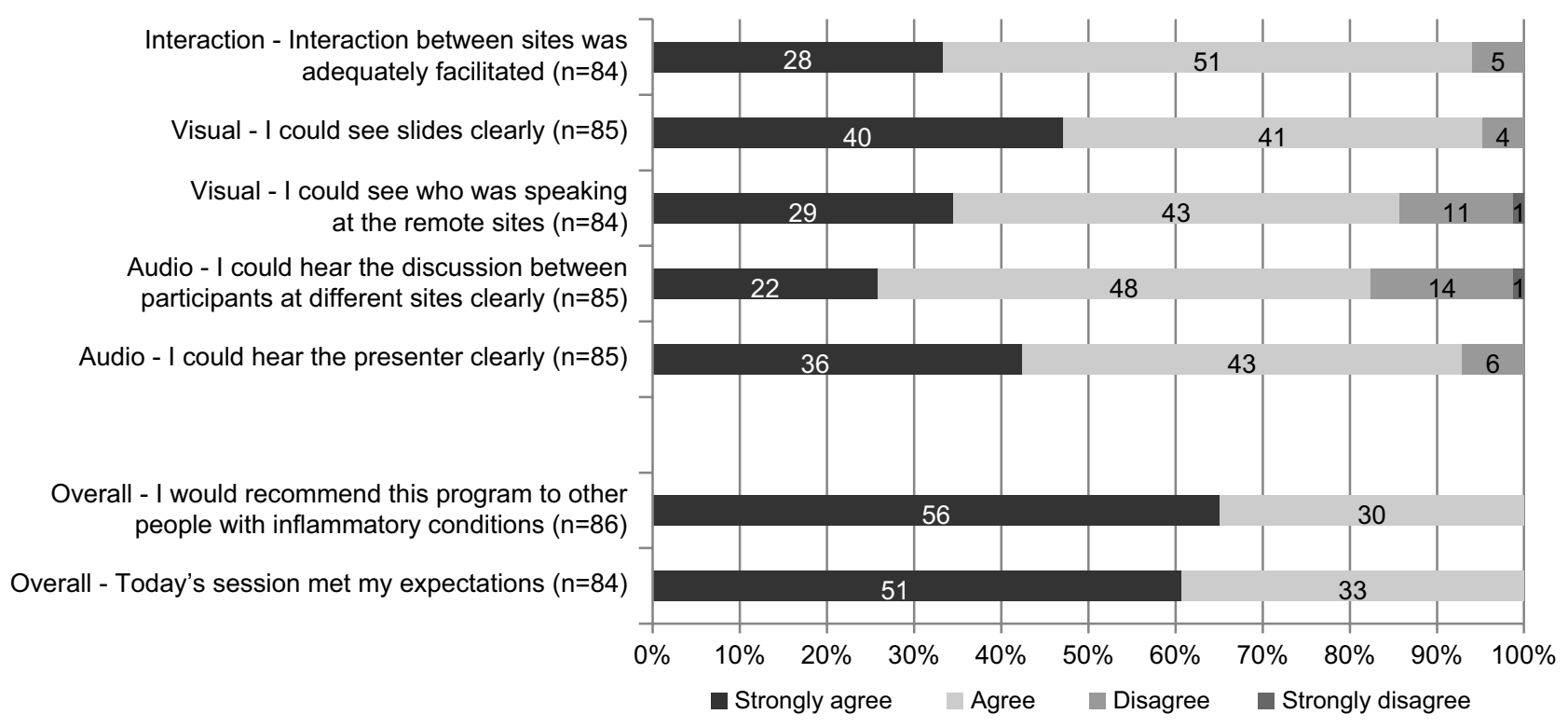

Figure I Remote participants' perception of videoconferencing.

$(\mathrm{n}=45,52.3 \%)$, and lived with at least one other person $(\mathrm{n}=67 ; 78.8 \%)$. The majority of these participants had been diagnosed with RA ( $n=60,85.7 \%$ ), either on its own or in conjunction with PsA, SLE, or IBD. Disease duration varied with a mean of 7.9 years $(\mathrm{SD}=11.2)$. Mean disease activity was $4.7(\mathrm{SD}=1.8)$ and HAQ score $0.6(\mathrm{SD}=0.4)$, indicating little disability.

The vast majority of participants reported $(\%$ who agreed or strongly agreed) that they could hear the presenter $(\mathrm{n}=79$, $92.9 \%$ ) as well as the discussion between sites ( $\mathrm{n}=70,82.4 \%$ ). Most could see who was speaking at the other remote sites $(\mathrm{n}=72,85.7 \%)$, and they could see the presenters' slides $(\mathrm{n}=81,95.3 \%)$. Most felt that interaction between sites was adequately facilitated $(n=79,94.0 \%)$. Overall, $100 \%$ of respondents reported that the session met their expectations and, similarly, that they would recommend the program to other people with IA (Figure 1).

\section{Post-program faculty (educator/ facilitator) feedback}

Between four and ten educators/facilitators submitted reflective feedback after the three RxEd sessions. Depending on their availability, a subset of the educators, facilitators, and the research team participated in each of the three debriefing meetings.

Educator and facilitator feedback validated the program evaluation data. Feedback suggested that having local facilitators to manage the videoconference technology was essential and that the overall coordination of the program content, technology, and flow of the day were very important and well managed. Facilitators noted that, for the most part, they and the attendees could see and hear the presenters well. They noted some challenges hearing comments from other sites and, as such, acknowledged the importance of the educators repeating questions posed at other sites. Facilitators also requested that educators "treat the video camera as if it's a person," to encourage eye contact with the camera and therefore the remote participants. Some facilitators even took the opportunity to share their appreciation for being involved; they noted the psychological benefits of the program to remote attendees thanks to participant interaction, the expert content, and having their questions and fears addressed.

\section{Follow-up participant interviews}

Six participants from across the remote sites completed follow-up interviews. Demographics are not reported due to the small sample size. The six semi-structured interviews were conducted between 2 and 6 weeks after participants had attended the RxEd program. Interviews ranged in length from 5 to $15 \mathrm{~min}$.

Remote participants reflected on the value of the program, delivery via videoconference, and the impact or potential impact of RxEd. They noted that the program goes beyond the education that physicians and individual health care professionals can offer in a clinical setting:

... when it comes to arthritis [my doctor is] pretty vague ...

I knew absolutely nothing about what to expect ...

... [the program] was very content-rich ... Having the different experts talk about their perspective and their ability to 
input on treatment was quite useful in understanding ... It's an issue that has to be looked at from many perspectives ...

Remote participants note that the program is a good starting point and may be particularly valuable for those newly diagnosed:

... I've had arthritis for 10 years and I would have loved to have participated in this at the beginning. I went through a lot and this would have really helped me ...

Specific to the videoconference delivery of the program, remote participants noted that they would not have attended if the session was not offered in their community:

... I would have found it difficult to get [to Toronto]. I would have had to not attend just because of the drive ... The fact that it was available in the outlying areas ... was excellent for us and we so appreciate having the opportunity to participate ...

The small group setting and on-site facilitators supported learning:

... You probably could have sat at home and watched it on your computer. But I don't think it would have had the same opportunity for reinforcement, either by the facilitator or by the other people in the group ...

... you felt connected with your little group ... [That] removed some of the isolation ...

And while some participants felt included:

... I think that it was good that they allowed all the viewers to ask questions and provide feedback if they wanted to. It wasn't like you just sat and watched people. You were encouraged to participate ... I thought that was helpful ...

Others would have liked to see more discussion and interaction between the remote sites:

... we had to cover so much information in such a short time that I didn't feel like there was much of a time for .. discussion ...

Overall, participants reported that the facilitators were very competent with the technology:

... [The facilitator was] so encouraging for everybody and very comfortable with operating the equipment. There were no issues there ...

... [The facilitator] at our end ... was excellent ... Everything [was] organized and running smoothly ... There [were] no hang ups at all ...
The immediate and short-term impacts of the program were evident. Participants benefited from the peer interaction:

... I think it's always very positive to be with other people that have arthritis, in the same room ... you see different ages, you see people that don't look like they have arthritis $\ldots$ and it's kind of interesting to hear ... what they've gone through. It's very satisfying to have that experience ...

... the greatest value I got out of it was being there with people who were further down the path than I was who were saying 'it's going to get better' ...

The knowledge they gained positively impacted how they felt about their disease and its treatment:

... I came away feeling better about my meds and understanding why I'm taking what I'm taking and not feeling devastated ... And understanding how important the inflammatory drugs are to me ...

And some had made decisions about their care:

... I actually went there because I really needed to know more about this medication they were putting me on. I was really scared to go on it. After listening to all these things they had to say, I decided I would try it ...

\section{Discussion}

Patient education empowers individuals living with arthritis, as it helps them understand their chronic disease, and also offers strategies to self-manage their symptoms ${ }^{1,7-10}$ Unfortunately, there are many barriers, including distance and a lack of qualified health care human resources, which prevent patients from accessing appropriate, comprehensive education. In the present study, the issue of access was addressed by offering the RxEd program to individuals with IA, in their communities. Delivering the education program, via videoconferencing technology, with the support of specialized arthritis facilitators was feasible, well-received, and as effective as in-person delivery of the content. ${ }^{34}$ Participants provided rich feedback addressing the technology, the immediate and short-term impacts of the program, and the unanticipated benefits associated with peer interaction and the presence of the facilitators.

Of note, all the respondents reported that they would recommend the program to other people with IA. Educator and facilitator feedback aligned with the strengths and weaknesses of the program and the technology identified by the participants. Program modifications between sessions addressed weaknesses where possible and reinforced the use of a quality improvement approach to meet participants' needs. Finally, 
in addition to some constructive feedback about sound quality and remote site inclusion, interview data focused on the value of the program, including the knowledge gained, social support, and the benefits of education, which would have been wholly inaccessible if not offered via telemedicine.

This study had some limitations. First, the number of qualitative interviews was low. Additional participant feedback and more responses from each site would strengthen the conclusions drawn. Another limitation of this work is the potential bias associated with the educator and facilitator feedback. Some of the educators and facilitators are also members of the research team. Finally, the exclusion of individuals who could not provide data in English is also a limitation. The present study recognized that people with chronic conditions who are living in remote areas and whose first language is not English are a highly vulnerable population. They utilize the health care system at a disproportionately high rate and would very likely benefit from accessible, targeted, culturally sensitive patient education. It is hoped that the model of telemedicine delivery that has been used can serve as the foundation for the development of other such arthritis education programs. This is an opportunity for future research.

The strengths of this study include the strong response rate (program evaluation: 82\%) and representation from across sites in the qualitative interview data. The present study has three rich sources of data from different stakeholders and time points that allowed for triangulation of study findings. This mixed-methods approach validated previous and early findings and uncovered new information about the impact of the RxEd Program when delivered remotely. Finally, an iterative approach to program improvement grounded in quality improvement methodology was taken. Addressing participant feedback from one session to the next allowed later attendees to benefit from ongoing modifications and encouraged attendees and educators/facilitators to generate new improvement ideas over the course of the three sessions.

The use of videoconferencing for distance education makes the delivery of educational opportunities more accessible to health care professionals living and working in remote areas. Compared to other distance learning modalities - online learning and webinars - videoconferencing is considered the richest media because the technology allows for the conveyance of communication cues (eg, vocal inflection and gestures) and real-time communication. ${ }^{40,41}$ While videoconferencing has become more commonplace, educators are still challenged to use the medium effectively. As a result, the technology can interfere with the learning experience. The artificiality of videoconferencing technology is often blamed for an unsatisfactory learning experience. However, the way the course is planned, and a lack of knowledge, on the part of the adult educator, about how to engage the remote audience can adversely affect the quality of the virtual educational experience as well. ${ }^{42}$ Lecture format, in particular, has been shown to leave remote participants feeling excluded from discussions, emotionally isolated, and reluctant to ask questions or to discuss issues. ${ }^{42}$ The literature suggests that the introduction of a more participatory pedagogy is better suited to this interactive medium. ${ }^{43,44}$ In the present study, the videoconferencing professional development workshops were an effective intervention that prepared the educators to embrace the media-rich features of the technology. The workshops supported them to integrate participatory education practices in order to ensure that all learners were immersed in the learning experience.

\section{Conclusion}

Our study showed that it is feasible to deliver an effective RxEd workshop by using multipoint videoconferencing. Participants and educators saw value in offering RxEd to remote sites using telemedicine. By taking full advantage of the functionality of the videoconferencing medium, the educators were able to encourage active participation and effectively engage learners regardless of their geographical location. The creation of the virtual learning environment made it possible for remote participants to gain new knowledge about their condition from specialized, interprofessional health care providers and, importantly, gave them an opportunity to interact with and learn from their peers.

\section{Future directions}

Although the present study demonstrated that it was feasible to use interactive videoconferencing to deliver an effective patient education program, it was acknowledged that facilitation of day-long workshops for targeted communities poses logistical challenges, is costly and time-intensive, and may be exclusionary. As our population ages, the prevalence of chronic diseases, such as IA, is anticipated to increase, as will be the demand for accessible, high-quality patient education. This raises a number of questions related to the reach and sustainability of programs such as RxEd. Future research should further examine: curriculum design (such as shortening the workshop or offering the program as a series of sessions); alternative formats developed as an adjunct (such as web-based learning: eLearning, webcasting); a blended learning approach combining in-person or video-based peer interaction and self-selected, asynchronous, online education as an even more accessible and sustainable option; whether a blended learning approach would achieve similar outcomes; and finally whether tailored, needs-based patient education 
would improve self-efficacy and health status in this population as in others..$^{45}$

There are innumerable opportunities for future study. While leveraging the expertise of ACPAC-trained health care providers, the lived experience and recommendations of patients and clinicians in remote areas, and the benefits of ever-advancing technology, RxEd has the potential to benefit a significant number of individuals with IA. Ideally, the RxEd program will continue to grow and adapt, based on patient needs, within a sustainable framework.

The need for patient education among adults with IA will continue to grow. Delivering the RxEd program via telemedicine offers a feasible and effective solution to this growing demand in remote areas across Ontario.

\section{Acknowledgments}

This work was supported by CIORA (Canadian Initiative for Outcomes in Rheumatology Care), 2012-2013 funding cycle. The authors thank (time, program delivery, intellectual contribution): St. Michael's Hospital RxEd team: Dr. Louise Perlin, Angelo Papachristos, Rosaleen Crooks, Caroline Jones, Maureen Riley, Melissa Heidebrecht, Sasha Miles, Donna Scaffidi, Josie Rockman, Catherine Walther, Kevin Curley; Rural/Remote Ontario sites: Jocelyne Murdoch, Mary Ellen Marcon, Tiffany Larsen, Anne MacLeod, Lisa Denning; and St. Michael's Telemedicine team: Mark Kinach, Rashmi Bhide.

\section{Disclosure}

Preliminary findings from this paper were presented at the following meetings as a conference talk:

1. e-Health 2015: Making Connections, Toronto, Ontario. The presentation is posted at http://www.e-healthconference. com/pastpresentations/2015/201571077557/1931Cflewe lling RxEdTelemed 2015 COACH.pdf?AF=Download $\underline{\& A A}=202,1502 \& A D=$ D1File

2. 2nd Annual Sunnybrook Education Conference 2013: Digital Learning, Toronto, Ontario. Abstracts/presentations from this meeting were not published or posted.

3. e-Health 2013: Accelerating Change, Toronto, Ontario. Abstracts/presentations from this meeting were not published or posted.

Preliminary findings from this paper were presented at the following meetings as a poster presentation:

1. Canadian Rheumatology Association/Arthritis Health Professions Association Annual Scientific Meeting 2014, Whistler, British Columbia. The poster's abstract (\#72) was posted at https://rheum.ca/images/documents/2014 Poster Presentations for JRheum.pdf

2. American College of Rheumatology/Association of Rheumatology Health Professionals (ACR/ARHP) Annual Meeting 2013, San Diego, California, USA. The poster's abstract (\#986) was published in the 2013 Annual Meeting Abstract Supplement. Arthritis \& Rheumatism, 65: S420 (abstract \#986). doi: 10.1002/ art.38216. http://www.acrannualmeeting.org/wp-content/ uploads/2014/01/2013-ACR ARHP-Annual-MeetingAbstract-Supplement.pdf

The authors report no other conflicts of interest in this work.

\section{References}

1. Bombardier C, Hawker G, Mosher D. The impact of arthritis in Canada: today and over the next 30 years. Arthritis alliance of Canada; 2011. Available from: www.arthritisalliance.ca/images/PDF/eng/../20111022_2200_ impact_of_arthritis.pdf. Accessed September 9, 2016.

2. The Arthritis Society. Facts and figures; 2015. Available from: http:// arthritis.ca/getmedia/43e83e3e-1a54-4fda-81d5-042ffaf9983f/ArthritisFacts-Figures-EN.pdf. Accessed September 8, 2016.

3. Statistics Canada. Population by sex and age group; 2016. Available from: http://www.statcan.gc.ca/tables-tableaux/sum-som/101/cst01/ demo31a-eng.htm. Accessed October 17, 2016.

4. Widdifield J, Paterson JM, Bernatsky S, et al. The rising burden of rheumatoid arthritis surpasses rheumatology supply in Ontario. Can J Public Health. 2013;104:e450-e455.

5. MacKay C, Veinot P, Badley EM. Characteristics of evolving models of care for arthritis: a key informant study. BMC Health Serv Res. 2008;8:147.

6. Gillis K, Augruso A, Coe T, et al. Physiotherapy extended-role practitioner for individuals with hip and knee arthritis: patient perspectives of a rural/urban partnership. Physiother Can. 2014;66:25-32.

7. Albano MG, Giraudet-Le Quintrec JS, Crozet C, d'Ivernois JF. Characteristics and development of therapeutic patient education in rheumatoid arthritis: analysis of the 2003-2008 literature. Joint Bone Spine. 2010;77:405-410.

8. Combe B, Landewe R, Lukas C, et al. EULAR recommendations for the management of early arthritis: report of a task force of the European Standing Committee for International Clinical Studies Including Therapeutics (ESCISIT). Ann Rheum Dis. 2007;66:34-45.

9. National Institute for Health and Care Excellence (NICE). Rheumatoid arthritis: the management of rheumatoid arthritis in adults; 2009. Available from: https://www.nice.org.uk/guidance/cg79. Accessed September 9, 2016.

10. Zangi HA, Ndosi M, Adams J, et al. EULAR recommendations for patient education for people with inflammatory arthritis. Ann Rheum Dis. 2015;74:954-962.

11. Barlow JH, Pennington DC, Bishop PE. Patient education leaflets for people with rheumatoid arthritis: a controlled study. Psychol Health Med. 1997;2:221-235.

12. Bell MJ, Lineker SC, Wilkins AL, Goldsmith CH, Badley EM. A randomized controlled trial to evaluate the efficacy of community based physical therapy in the treatment of people with rheumatoid arthritis. J Rheumatol. 1998;25:231-237.

13. Branch V, Lipsky K, Nieman T, Lipsky P. Positive impact of an intervention by arthritis patient educators on knowledge and satisfaction of patients in a rheumatology practice. Arthritis Care Res. 1999;12:375.

14. Helliwell PS, O'Hara M, Holdsworth J, Hesselden A, King T, Evans P. A 12-month randomized controlled trial of patient education on radiographic changes and quality of life in early rheumatoid arthritis. Rheumatology (Oxford). 1999;38:303-308. 
15. Lindroth Y, Brattstrom M, Bellman I, et al. A problem-based education program for patients with rheumatoid arthritis: evaluation after three and twelve months. Arthritis Care Res. 1997;10:325-332.

16. Lorig K, Feigenbaum P, Regan C, Ung E, Chastain RL, Holman HR. Comparison of lay-taught and professional-taught arthritis self-management courses. J Rheumatol. 1986;13:763-767.

17. Taal E, Riemsma RP, Brus HLM, Seydel ER, Rasker JJ, Wiegman O. Group education for patients with rheumatoid arthritis. Patient Educ Couns. 1993;20:177-187.

18. Lorig DR, Mazonson PD, Holman HR. Evidence suggesting that health education for self-management in patients with chronic arthritis has sustained health benefits while reducing health care costs. Arthritis Rheum. 1993;36:439-446.

19. Lorig KR, Lubeck D, Kraines RG, Seleznick M, Holman HR. Outcomes of self-help education for patients with arthritis. Arthritis Rheum. 1985;28:685

20. Leibing E, Pfingsten M, Bartmann U, Rueger U, Schuessler G. Cognitive-behavioral treatment in unselected rheumatoid arthritis outpatients. Clin J Pain. 1999;15:58-66.

21. Parker JC, Smarr KL, Buckelew SP, et al. Effects of stress management on clinical outcomes in rheumatoid arthritis. Arthritis Rheum. 1995;38:1807-1818.

22. Savelkoul M, De Witte LP, Van der Borne BHW, Van der TH. Effects of a coping intervention on patients with rheumatic diseases: results of a randomized controlled trial. Arthritis Rheum. 2001;45:69-76.

23. Scholten C, Brodowicz T, Graninger W, et al. Persistent functional and social benefit 5 years after a multidisciplinary arthritis training program. Arch Phys Med Rehabil. 1999;80:1282-1287.

24. Sharpe L, Sensky T, Timberlake N, Ryan B, Brewin CR, Allard S. A blind, randomized, controlled trial of cognitive-behavioural intervention for patients with recent onset rheumatoid arthritis: preventing psychological and physical morbidity. Pain. 2001;89:275-283.

25. Bodenheimer T, Lorig K, Holman H, Grumbach K. Patient self-management of chronic disease in primary care. JAMA. 2002;288:2469-2475.

26. Kennedy CA, Beaton DE, Warmington K, Shupak R, Jones C, HoggJohnson S. Prescription for education: development, evaluation, and implementation of a successful interprofessional education program for adults with inflammatory arthritis. J Rheumatol. 2011;38:2247-2257.

27. Jaglal SB, Haroun VA, Salbach NM, et al. Increasing access to chronic disease self-management programs in rural and remote communities using telehealth. Telemed J E Health. 2013;19:467-473.

28. Huijbregts MPJ, McEwen S, Taylor D. Exploring the feasibility and efficacy of a telehealth stroke self-management programme: a pilot study. Physiother Can. 2009;61:210-220.

29. Taylor DM, Cameron JI, Walsh L, et al. Exploring the feasibility of videoconference delivery of a self-management program to rural participants with stroke. Telemed J E Health. 2009;15:646-654.

30. Izquierdo RE, Knudson PE, Meyer S, Kearns J, Ploutz-Snyder R, Weinstock RS. A comparison of diabetes education administered through telemedicine versus in person. Diabetes Care. 2003;26:1002-1007.
31. Kearns JW, Bowerman D, Kemmis K, Izquierdo RE, Wade M, Weinstock RS. Group diabetes education administered through telemedicine: tools used and lessons learned. Telemed JE Health. 2012;18: $347-353$.

32. Timmerberg BD, Wurst J, Patterson J, Spaulding RJ, Belz NE. Feasibility of using videoconferencing to provide diabetes education: a pilot study. J Telemed Telecare. 2009;15:95-97.

33. West SP, Lagua C, Trief PM, Izquierdo R, Weinstock RS. Goal setting using telemedicine in rural underserved older adults with diabetes: experiences from the informatics for diabetes education and telemedicine project. Telemed J E Health. 2010;16:405-416.

34. Kennedy CA, Warmington K, Flewelling C, et al. A prospective comparison of telemedicine versus in-person delivery of an interprofessional education program for adults with inflammatory arthritis. $J$ Telemed Telecare. Published online before print March 7, 2016.

35. Lundon K, Shupak R, Sunstrum-Mann L, Galet D, Schneider R. Leading change in the transformation of arthritis care: development of an inter-professional academic-clinical education training model. Healthc Q. 2008;11:62-68.

36. Fransen J, Stucki G, van Riel PLCM. Rheumatoid arthritis measures: Disease Activity Score (DAS), Disease Activity Score-28 (DAS28), Rapid Assessment of Disease Activity in Rheumatology (RADAR), and Rheumatoid Arthritis Disease Activity Index (RADAI). Arthritis Care Res. 2003;49:S214-S224.

37. Fries JF, Spitz PW, Kraines RG, Holman HR. Measurement of patient outcome in arthritis. Arthritis Rheum. 1980;23:137-145.

38. Stanford School of Medicine. Research instruments developed, adapted or used by the Stanford Patient Education Research Center. Paolo Alto, CA: Standford School of Medicine; 2010 [cited October 14, 2010]. Available from: http://patienteducation.stanford.edu/research/. Accessed September 8, 2016.

39. Health Quality Ontario. Quality Improvement Guide; 2012. Available from: http:/www.hqontario.ca/portals/0/documents/qi/qi-qualityimprove-guide-2012-en.pdf. Accessed September 8, 2016.

40. Daft RL, Lengel RH. Organizational information requirements, media richness and structural design. Manag Sci. 1986;32:554-571.

41. Dennis AR, Kinney SD. Testing media richness theory in the new media: the effects of cues, feedback and task equivocality. ISR. 1986;9: 256-274.

42. Knipe D, Lee M. The quality of teaching and learning via videoconferencing. British J Educ Technol. 2002;33:301-311.

43. Fritzw Y, Nordkvelle YT. Comparing lectures: effects of the technological context of the studio. Educ and Info Technol. 2003;8:327-343.

44. Sclater K, Alagiakrishnan K, Sclater A. An investigation of videoconferenced geriatric medicine grand rounds in Alberta. JTelemed Telecare. 2004;10:104-107.

45. Ndosi M, Johnson D, Young T, et al. Effects of needs-based patient education on self-efficacy and health outcomes in people with rheumatoid arthritis: a multicentre, single blind, randomised controlled trial. Ann Rheum Dis. 2016;75:1126-1132.
Open Access Rheumatology: Research and Reviews

\section{Publish your work in this journal}

Open Access Rheumatology: Research and Reviews is an international, peerreviewed, open access journal publishing original research, reports, editorials, reviews and commentaries on all aspects of clinical and experimental rheumatology in the clinic and laboratory including the following topics: Pathology, pathophysiology of rheumatological diseases; Investigation, treatment and management of rheumatological diseases; Clinical trials and novel pharmacologi$\mathrm{cal}$ approaches for the treatment of rheumatological disorders. The manuscript management system is completely online and includes a very quick and fair peer-review system, which is all easy to use. Visit http://www.dovepress.com/ testimonials.php to read real quotes from published authors. 